\title{
Effects of chemical modifications on the rheological and the expansion behavior of polylactide (PLA) in foam extrusion
}

https://doi.org/10.1515/epoly-2019-0030

Received October 24, 2018; accepted December 17, 2018.

\begin{abstract}
It is well known that polylactide (PLA) is difficult to foam due to its low melt strength. Thus, many ways were described in the literature to enhance the foamability. However, the melt strength was actually determined only in a limited number of publications. In this study, the addition of chemical modifiers was used to change the rheological behavior of PLA and thereby improve its foamability in foam extrusion process. For the first time the use of dicumyl peroxide modified PLA in foam extrusion is described. Both modifications lead to a distinct increase in melt strength. Here, the highest increase was shown for the PLA modified with dicumyl peroxide. Furthermore, strain hardening was observed for PLA modified with the peroxide. Low density foams were achieved for neat and modified PLA in foam extrusion. Neat PLA showed a density of $45 \mathrm{~kg} / \mathrm{m}^{3}$, while the peroxide modified PLA showed the highest expansion with a density reduction down to $32 \mathrm{~kg} / \mathrm{m}^{3}$. Both modifications result in a more uniform cell structure and an improved compression strength. Here, the foamed, peroxide modified PLA showed outstanding performance compared to neat PLA foam with twice the compression strength (151 Pa) even at a 30\% lower density.
\end{abstract}

Keywords: polylactide; biofoams; chemical modification; melt strength; foam extrusion; compression behavior

\footnotetext{
* Corresponding author: Volker Altstädt, Department of Polymer Engineering, University of Bayreuth Universitätsstraße 30, 95447 Bayreuth - Germany, e-mail: altstaedt@uni-bayreuth.de.

Tobias Standau, Agathe Delavoie, Department of Polymer Engineering, University of Bayreuth Universitätsstraße 30, 95447 Bayreuth - Germany.

Svenja Murillo Castellón, Christian Bonten, Institut für Kunststofftechnik, University of Stuttgart Pfaffenwaldring 32, 70569 Stuttgart - Germany.
}

\section{Introduction}

Nowadays, the majority of produced plastics are still based on fossil resources. To save these resources and to establish fossil carbon free alternatives the interest in biopolymers is growing steadily. In 2013, bioplastics had a capacity of $2 \%$ of the world production of polymers. However, it is expected that the amount increases to $4 \%$ until 2020 (1). PLA is a bio-based and biodegradable polyester with mechanical properties similar to polystyrene (PS) (2), which is often used in packaging and insulation applications as a polymer foam. Not taking into account bioplastics that are not biodegradable (so called drop-in polymers like bio-PET, bio-PE, etc.), polylactide (PLA) is currently the most important bioplastic with a production capacity of 450,000 tons per year (3). However, PLAs low melt strength (4) is disadvantageous for processes that involve elongation / stretching of the melt, like foaming. Effective ways to overcome this issue have been summarized by M. Nofar and C.B. Park; this includes the introduction of a chain extender that can induce the formation of branched or even cross-linked structures, the modification of D/L-PLA ratio, control of crystallization behavior, the variation of the molecular weight and the addition of additives (5).

As often described in the literature, chemical melt modification (i.e., reactive extrusion) is an efficient way to increase the melt strength. Yet a wide variety of suitable substances has been investigated. In general, these modifiers can be distinguished in two groups depending on the induced mechanism; namely (i) functional group reaction or (ii) free radical reaction. Typical examples for chemical modifiers, which enable functional group reactions are - amongst many others - epoxides (6-9), diisocyantes $(10,11)$ and dianhydrides $(12,13)$. Free radical reactions can be initiated by irradiation or addition of substances which are able to generate free radicals such as peroxides $(14,15)$. 
Commercial chain extenders like the multifunctional epoxide Joncryl 4368 ADR (BASF SE) were already studied in autoclave foaming (16) and foam extrusion (17). Corre et al. (16) found that with increasing chain extender content a higher density reduction was possible in the case of autoclave foaming (pressure drop method). More uniform foam structures, smaller cell sizes and expansion ratios of 40 were reported for PLA extrusion foams modified with $0.7 \mathrm{wt} \%$ chain extender (17). The modification with chain extender clearly leads to an increased melt viscosity due to the formation of non-linear chain extended structures, as reported in our previous work (18). The epoxide groups of the chain extender are opened during melt processing and can react with the carboxyl and the hydroxyl groups at the chain ends of PLA to form covalent bondings (19). Depending on functionality and concentration of the chain extender, chain branching could happen $(19,20)$. Also crosslinking was reported for the chain extender Joncryl (21).

On the other hand, the mechanism of peroxides differs. In a first step the peroxide decomposes under heat and forms primary radicals which can then abstract hydrogen atoms from PLA. Afterwards, the so formed PLA radicals can recombine with each other and form $\mathrm{C}-\mathrm{C}$ bondings $(15,22)$. Dicumyl peroxide exhibits a comparably slow decomposition rate and a high hydrogen abstraction ability. It can result in various chain structures such as linear, star-, comb- or tree-like structures (23). This depends on the amount of the peroxide. The work of Södergård (24) showed that below $0.25 \mathrm{wt} \%$ branching is predominant while above $0.25 \mathrm{wt} \%$ significant crosslinking can be expected. In a former study (25) we could show, that thermal and rheological behavior significantly change by the addition of different chemical modifiers, like dicumyl peroxide.

Studies on peroxides, like lauroyl peroxide, showed that $1 \mathrm{wt} \%$ increased the melt strength of PLA by a factor of three (26). For autoclave foaming, Yu et al. (13) observed much smaller cell sizes (average diameter $52 \mu \mathrm{m}$ ) for PLA modified with $0.3 \mathrm{wt} \%$ of lauroyl peroxide.

Previously, this peroxide was used by Huang et al. (27) as a cross-linker in PLA natural rubber blends to enhance their mechanical properties; e.g., improving the tensile toughness, elongation-at-break and impact strength. It was found that the complex viscosity could be increased by about one order of magnitude with adding $0.5 \mathrm{wt} \%$ peroxide. A higher peroxide content resulted in a higher degree of cross-linking. However, to our best knowledge this promising modifier was not used in foam extrusion of PLA so far.

Even though it is known that an increase in the melt strength is essential for the foaming of PLA with homogeneous cell size only a few studies quantify the melt strength of neat and modified PLA at all $(13,26,28)$. Furthermore, only limited work was done on the compression behavior of PLA foams (29). The main goal of this study was to investigate the effect of two selected modifications (multifunctional epoxide and peroxide) on the rheological properties (e.g., shear- / elongational viscosity, melt strength) and how this consequently can affect (i) the expansion behavior (e.g., density reduction, cell morphology) and (ii) the foam properties (e.g., compression behavior) of PLA extruded foams.

\section{Experimental}

\subsection{Materials}

In this study, PLA Ingeo TM 7001D from NatureWorks LLC (Minnetoka, MN, USA) was modified with two different chemical modifiers. A commercially available polymeric chain extender (Joncryl 4368 ADR, BASF SE, Ludwigshafen, Germany), which is a multifunctional epoxide (mEP), and dicumyl peroxide (PER) from Sigma Aldrich were studied. Both modifiers were incorporated by reactive extrusion with a ZSK 26 twin screw extruder (Coperion GmbH, Stuttgart, Germany). The concentrations were selected based on pre-trials with $1.0 \mathrm{wt} \%$ for the chain extender and $0.2 \mathrm{wt} \mathrm{m} \%$ for the peroxide. As described in a former study (25), the addition of the modifiers leads to an increase of molecular weight from 130,400 g/mol (neat PLA) to $200,600 \mathrm{~g} / \mathrm{mol}$ (PLA+mEP) and 237,600 g/mol (PLA+PER), respectively. Also, topological changes of the polymer chains were described in our previous studies $(25,30)$.

\subsection{Rheological investigation}

Frequency sweep measurements were carried out with plate-plate method on RMS500 rheometer from Rheometrics (Rheometric Scientific, New Castle, USA) at a temperature of $180^{\circ} \mathrm{C}$ (nitrogen atmosphere, gap size of $1.0 \mathrm{~mm}$, diameter of $25 \mathrm{~mm}$ and $1 \%$ strain). The measurements were carried out in a frequency range from 500 to $0.01 \mathrm{rad} / \mathrm{s}$.

Furthermore, experiments to determine the behavior under elongational flow were conducted. The elongational viscosity was determined by measurements on a rheometer with a Universal Extension Fixture (UXF) (MCR 702, Anton Paar GmbH, Graz, Austria) on melt pressed samples $\left(10 \times 14 \times 0.5 \mathrm{~mm}^{3}\right)$ at $160^{\circ} \mathrm{C}$ at various strain rates $\left(0.1\right.$ to $\left.3 \mathrm{~s}^{-1}\right)$. 
Additionally, Rheotens measurements were carried out to determine the melt strength of the materials. Therefore, the polymer is pressed verticular through the die $(\mathrm{l}=30 \mathrm{~mm}, \mathrm{~d}=2 \mathrm{~mm}$ ) of a capillary rheometer (Rheograph 6000, Göttfert Werkstoff-Prüfmaschinen GmbH, Buchen, Germany) at temperatures of $175^{\circ} \mathrm{C}$ or $185^{\circ} \mathrm{C}$. The temperatures were chosen to avoid die swell or sagging of the strand to prevent internal stresses in the strand. The strand is drawn down with a constant acceleration of $12 \mathrm{~mm} / \mathrm{s}^{2}$ by two counter-rotating wheels of the Rheotens 71.97 device (Göttfert Werkstoff-Prüfmaschinen $\mathrm{GmbH}$, Buchen, Germany) which is located below the capillary rheometer. Thus, the strand is subjected to uniaxial deformation. The wheel pairs are connected to a force transducer in order to measure the tensile force applied to the stretched strand. Then, tensile force is plotted as a function of the draw down velocity. The resistance of the melt against stretching (maximum average force before breakage) is defined as melt strength.

\subsection{Foam extrusion}

A tandem extrusion line (Dr. Collin GmbH, Ebersberg, Germany) was used for foaming, consisting of a twinscrew extruder $(\mathrm{L} / \mathrm{D}=42, \mathrm{D}=25 \mathrm{~mm})$, followed by a single-screw cooling extruder $(\mathrm{L} / \mathrm{D}=30, \mathrm{D}=45 \mathrm{~mm})$ with $3 \mathrm{~mm}$ round die. As also reported in the literature, a rather high concentration of $8 \mathrm{wt} \%$ carbon dioxide $\left(\mathrm{CO}_{2}\right)$ was injected as blowing agent in the twin-screw extruder $(31,32)$. The temperature in the twin-screwextruder was set to $200^{\circ} \mathrm{C}$. Due to the incorporation of $\mathrm{CO}_{2}$ $\mathrm{T}_{\mathrm{g}}$ and $\mathrm{T}_{\mathrm{m}}$ decrease significantly (33) allowing rather low temperatures of $160^{\circ} \mathrm{C}$ or $140^{\circ} \mathrm{C}$ in the second extruder. The individual modification and the mass temperature, which is influenced by the occurring shear, limited the further reduction of the die temperature.

\subsection{Differential scanning calorimetry (DSC)}

The thermal behavior was investigated with a DSC 1 from Mettler Toledo (Columbus, USA). Measurements were carried out in a range of 25 to $200^{\circ} \mathrm{C}$ at a heating rate of $10 \mathrm{~K} / \mathrm{min}$ under nitrogen atmosphere. The crystallinity was calculated from the melting enthalpy for a 100\% crystalline PLA homopolymer, $\Delta \mathrm{H}_{\mathrm{m}}=93.1 \mathrm{~J} / \mathrm{g}$ (4).

\subsection{Foam morphology}

Cryogenic fractured and gold sputtered foam samples were investigated by SEM (JEOL JSM-6510 Akishima, Japan) at an acceleration voltage of $10 \mathrm{kV}$. Cell sizes were determined by the use of an image analysis software (ImageJ, v1.48). The density was determined according to the Archimedes principle (AG245, Mettler Toledo, Columbus, USA).

\subsection{Mechanical analyses}

The compression behavior of samples cut from the foamed strands was determined in accordance to DIN 53421. Specimens were prepared by cutting out cylinders $(\mathrm{d}=8 \mathrm{~mm}, \mathrm{~h}=8 \mathrm{~mm}$ ) with a hollow drill in the extrusion direction. In this manner, the compact outer layer was removed. Ten compression tests for each material were performed on a universal test machine (Z2,5; Zwick GmbH \& Co.KG, Ulm, Germany) with a $500 \mathrm{~N}$ load cell at $25^{\circ} \mathrm{C}$, a constant compression rate of $0.8 \mathrm{~mm} / \mathrm{min}$ and an initial load of $1 \mathrm{~N}$.

\section{Results and discussion}

\subsection{Shear viscosity}

In Figure 1 the complex shear viscosity $|\eta|$ is shown as a function of the frequency $\omega$ for the neat PLA and the two modified PLA. Both modified PLA show a different flow behavior, which is due to their significantly higher average molecular weight and broader molecular weight distribution as described in our previous work (25). In the low frequency range, the complex viscosity is about a factor of ten higher than the neat PLA. Both modified PLA have a significant higher molecular weight than the neat PLA. Furthermore, they have more entanglements and

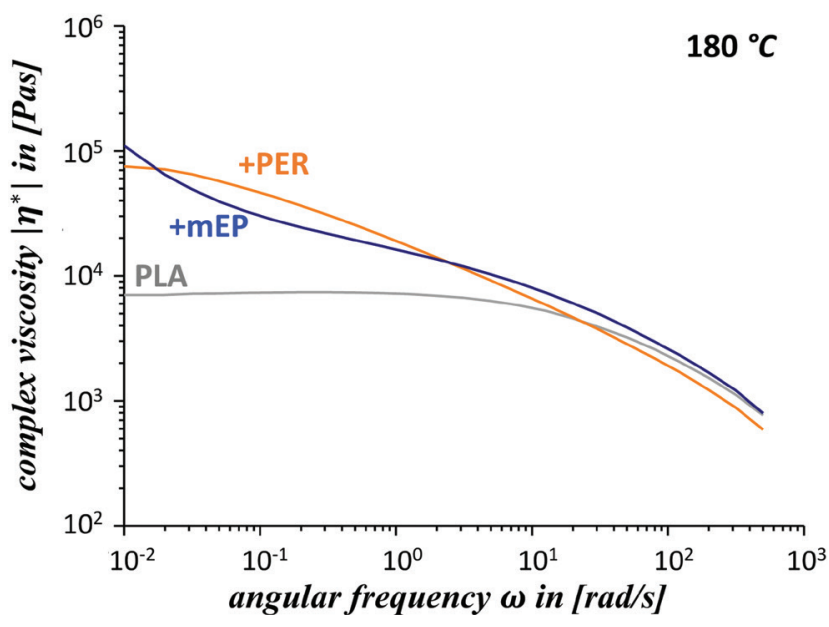

Figure 1: Frequency sweeps of neat and modified PLA @ $180^{\circ} \mathrm{C}$. 
higher relaxation times. Nevertheless, the flow behavior is quite different caused by different chain topologies.

PLA+PER shows a typical shear thinning behavior, while the Newtonian plateau is only indicated in the low frequency range and the shear thinning is much more pronounced. This indicates a significant longer relaxation time which can be attributed to a higher degree of chain entanglements. These entanglements hinder the flow in the low frequency range by building a physical network. This behavior can be attributed to the broader molecular weight distribution and / or to branched chains through modification.

PLA + mEP shows an s-shaped curve without forming a Newtonian plateau, which indicates the presence of a partially cross-linked structure. Although this indication for chemical cross-linking PLA+mEP can be thermoplastically processed. The hindered flow is here more pronounced than in PLA+PER which is the result of the chemical cross-links as shown in a previous work (25). The potential of the multi-functional chain extender to induce cross-linking was proven before $(21,34)$. Meng et al. (21) achieved cross-linked structures even at a rather low chain extender concentration of $0.5 \mathrm{wt} \%$. Here, the extent of cross-linking is stated to be highly dependent on the thermal degradation of the PLA chains as the newly formed hydroxyl and carboxyl end groups can react with the epoxy groups of the multi-functional chain extender. Li et al. reported analogous viscosity curves with a significant increase at lower frequencies also attributed to the occurring cross-linking (34). Interestingly, according to Huang et al. (27) similar rheological behavior can be found for dicumyl peroxide as well, but only at high concentrations above $0.5 \mathrm{wt} \%$.

\subsection{Elongational viscosity}

UXF results are shown in Figures $2 \mathrm{a}$ and $2 \mathrm{~b}$. During foaming processes, high strain rates of 1 to $5 \mathrm{~s}^{-1}$ are believed to occur (35). A comparison between neat and modified PLA at a strain rate of $3 \mathrm{~s}^{-1}$ is shown in Figure 2a. An increased elongational viscosity is clearly visible for both modified samples. Furthermore, neat PLA shows a plateau at higher strain, while the peroxide modified sample exhibits a significant increase in the viscosity. This strain hardening can be attributed to the chemical modification of the PLA chains with peroxide also resulting in the highest increase in molecular weight. Contrary to the linear chains of the unmodified PLA, a chain-topology with entanglements is created due to the use of the modifier (25). Figure $2 \mathrm{~b}$ shows PLA modified with the peroxide at different strain rates. Clearly, strain hardening as a result of entangled chains can be observed over a wide range of strain rates. Strain hardening is beneficial for foaming, because it stabilizes expanding cells. The reason for this is, that the entanglements get more contradicted the more the strain increases during the expansion. Practically, this means that the cell walls of the peroxide modified PLA can withstand a higher force during the expansion process. Hence, coalescence and cell rupture gets hindered. Thereby the branched structure induced by the peroxide can contribute to a more homogeneous cell structure.

\subsection{Melt strength}

The Rheotens curves of the neat PLA and both modified samples can be seen in Figure 3. It has to be mentioned that the measurements had to be done at different temperatures, which is a consequence of the narrow processing window of PLA. PLA and PLA+mEP were measured at $175^{\circ} \mathrm{C}$. Lower temperatures result in die swell while higher temperatures cause sagging of the strand. Because of the higher stiffness of the melt strand of PLA+PER the temperature for measurement had to be shifted to $185^{\circ} \mathrm{C}$ for this material.

It is observed that both modified PLA samples exhibit a decreased drawability / extensibility, as seen by the decrease in draw velocities at the point of strand rupture. Samples of neat PLA ruptured at $680 \mathrm{~mm} / \mathrm{s}$. Samples of PLA+mEP showed instabilities with increasing draw velocity and ruptured at $620 \mathrm{~mm} / \mathrm{s}$ while the strand made of PLA+PER already ruptured at $120 \mathrm{~mm} / \mathrm{s}$. The melt strength of the neat PLA was found to be very low at around $0.05 \mathrm{~N}$ and of PLA+mEP at about $0.07 \mathrm{~N}$. With both modifiers, it was possible to increase the melt strength considerably. The Rheotens curve of PLA+mEP shows some resonance at higher draw velocities. An even more distinct increase in the melt strength, with a value of $0.19 \mathrm{~N}$, was measured for PLA+PER. The increased melt strength of PLA+mEP and PLA+PER is attributed to the higher molecular weight and branched structures induced by the modifiers. Noteworthy the concentration of peroxide used in PLA+PER (0.2 wt\%) was set much lower than the concentration of the chain extender in PLA+mEP (1.0 wt $\%)$ concluding the peroxide is more efficient in enhancing the rheological properties.

\subsection{Foam properties}

The neat PLA as well as the modified materials were successfully processed by foam extrusion. The SEM 

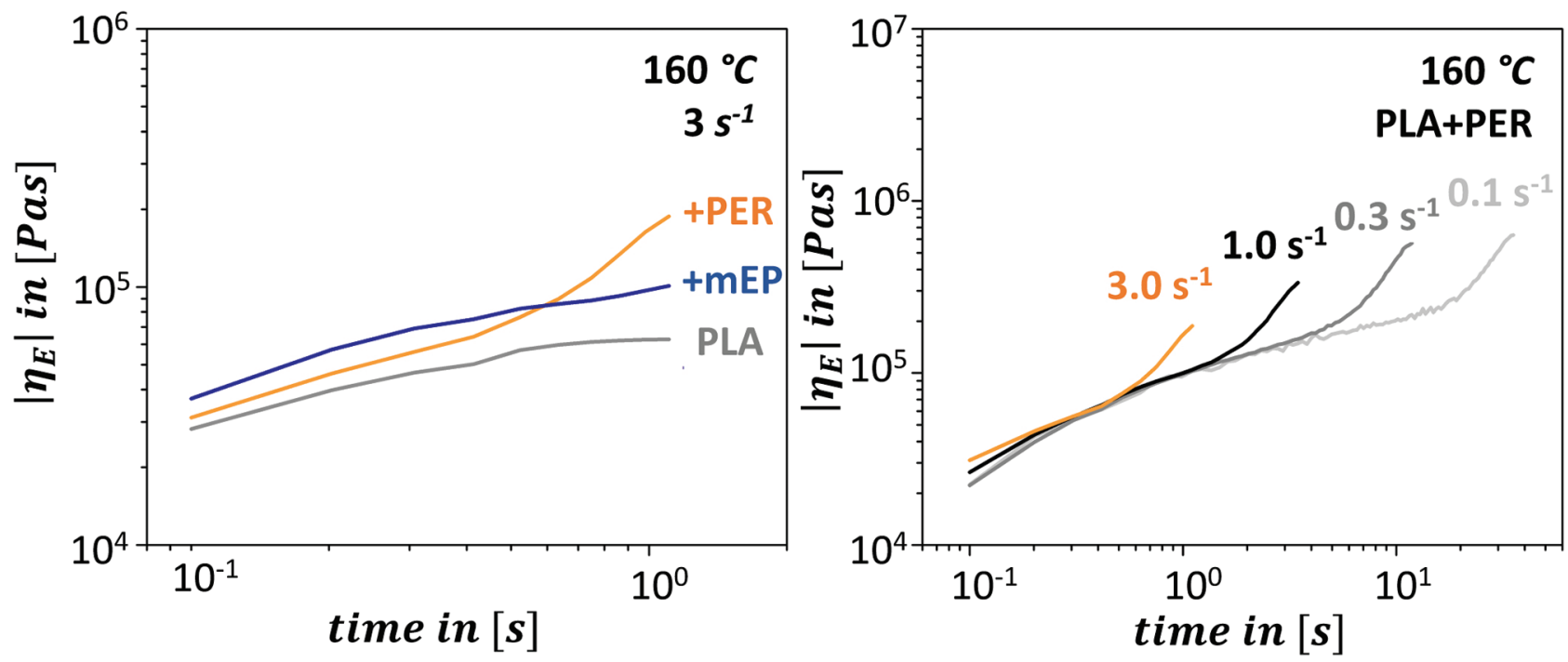

Figure 2: (a) Elongational viscosity curves of neat and modified PLA at a strain rate of $3.0 \mathrm{~s}^{-1}$ and $160^{\circ} \mathrm{C}$. (b) Elongational viscosity curves of PLA+PER at $160^{\circ} \mathrm{C}$ and strain rates from 0.1 to $3.0 \mathrm{~s}^{-1}$. (Please beware of the different dimensions of the axis).

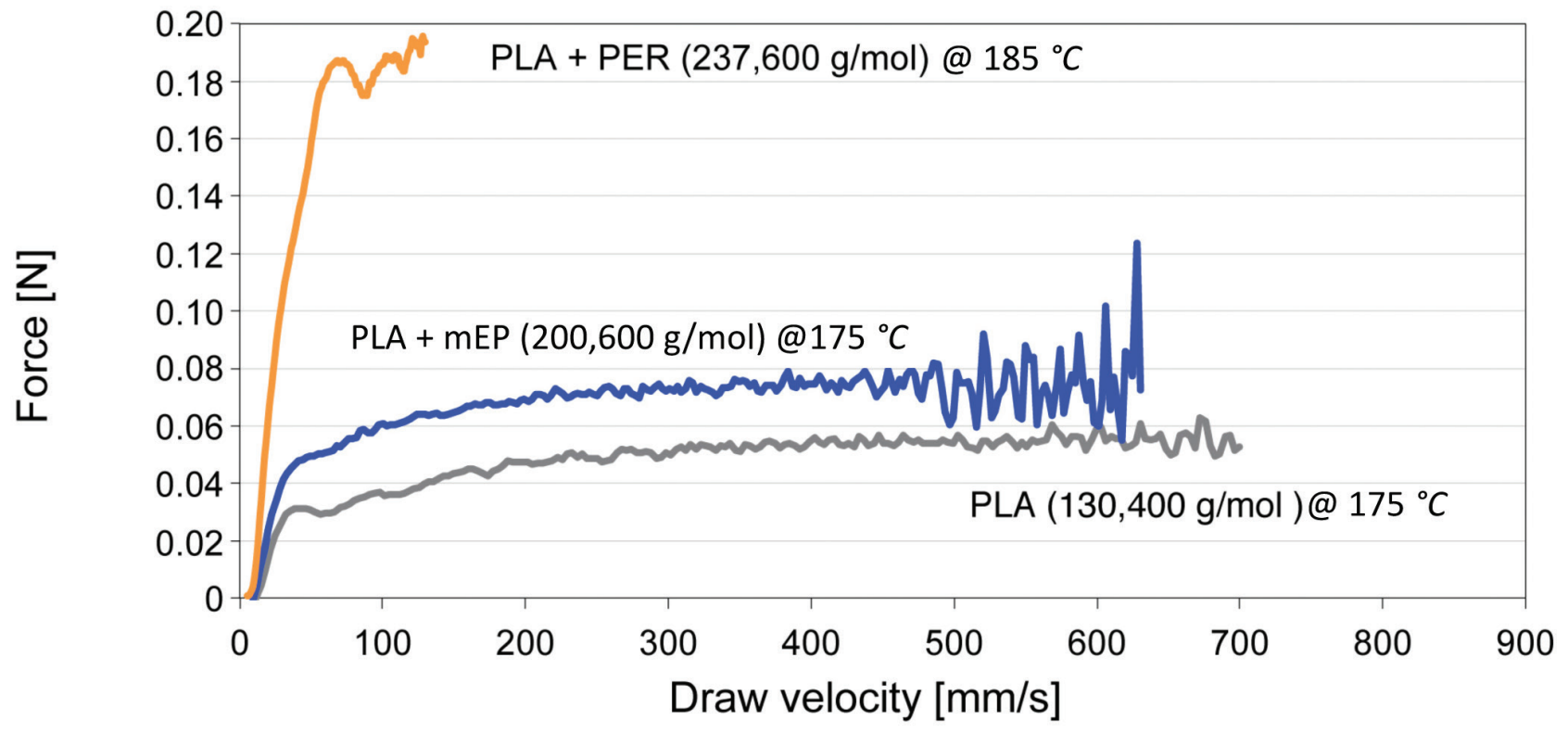

Figure 3: Rheotens curves of neat and modified PLA at $175^{\circ} \mathrm{C}(\mathrm{PLA}, \mathrm{PLA}+\mathrm{mEP})$ and $185^{\circ} \mathrm{C}(\mathrm{PLA}+\mathrm{PER})$.

images in Figure 4 show for each material the foam with the lowest density. The lowest achievable die temperature was $160^{\circ} \mathrm{C}$ for the neat PLA and $140^{\circ} \mathrm{C}$ for both modified PLA. This means, the processing window was widened by the incorporation of both modifiers. A broader foaming window was noted before by Yu et al. (13) during batch foaming experiments which was assigned to an increased melt strength. It is worth noting, that the unprocessed neat as well as the modified PLA showed amorphous behavior, but the extruded foams are clearly semi-crystalline with crystallinities $\chi$ of around $20 \%$. According to Mihai et al. the high crystallinities in foams can be attributed to higher crystallization rates induced by the biaxial stretching (so called strain induced crystallization) and the presence of $\mathrm{CO}_{2}$ as a plasticizer (36) during the processing.

The foams are mostly closed celled and cell walls are very thin. Clearly expansion and morphology are changing with adding both modifiers. The neat PLA and PLA $+\mathrm{mEP}$ foams had rather similar densities of $45 \mathrm{~kg} / \mathrm{m}^{3}$ and $49 \mathrm{~kg} / \mathrm{m}^{3}$, respectively, while the peroxide modification results in a much lower density of $32 \mathrm{~kg} / \mathrm{m}^{3}$. The foam morphology is rather coarse for neat PLA and shows cell rupture - a phenomenon known from the literature $(29,31)$. The high drawability (see Figure 3) allows neat 

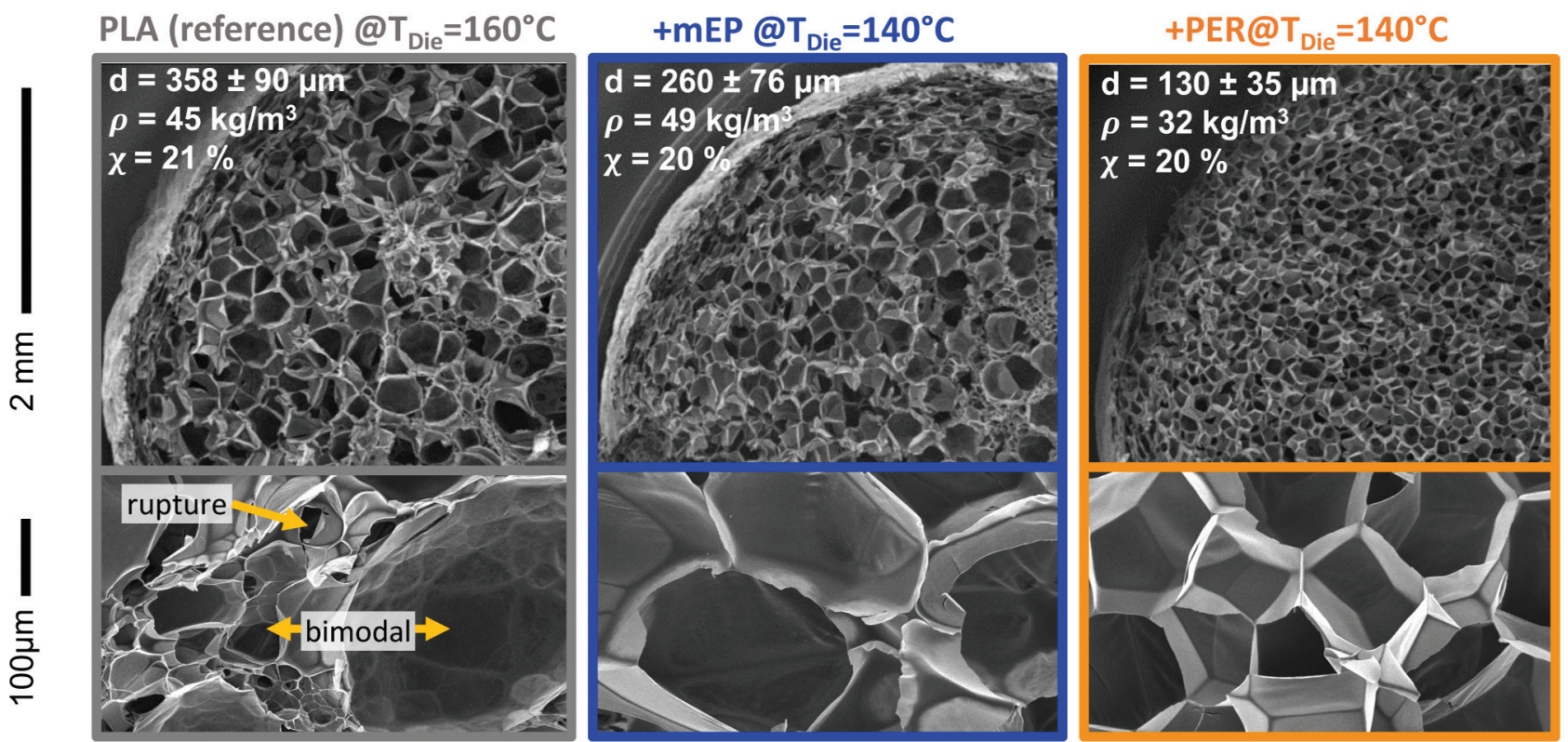

Figure 4: SEM images of the extrusion foams at two magnifications. Cell sizes and crystallinities $\chi$ are given in the corner.

PLA to expand distinctly resulting in the low density. While the foaming process, small cells (approx. $23 \mu \mathrm{m}$ ) tend to coalesce and form large bubbles $(358 \mu \mathrm{m})$. During cell growth, the cell walls cannot withstand the high occuring forces as a result of the low melt strength. By the addition of modifier, the morphology gets much finer. For PLA+mEP, the slightly reduced drawability combined with the increased melt strength lead to decreased cell size of $260 \mu \mathrm{m}$ and prevention of cell rupture. PLA+PER which showed the lowest drawability but the highest melt strength showed the highest expansion and the finest cells $(130 \mu \mathrm{m})$. It can be assumed, that the above-mentioned strain hardening acts beneficially for the homogeneity of PLA+PER foam as growing cells get stabilized uniformly.

In Figure 5 the stress-strain curves in compression are shown for the extrusion foams of neat and modified PLA. Higher foam stiffness was achieved with the foams from modified PLA. At 10\% deformation, the compression stress is $73 \pm 1 \mathrm{~Pa}$ for neat PLA. However, the compression stress for PLA+PER at the same deformation is $151 \pm 4 \mathrm{~Pa}$ and thereby twice as high and comparable with values for extruded polystyrene (XPS) (37). At the same time, it has to be mentioned, that PLA+PER with peroxide has a much lower density. The compression modulus $\mathrm{E}_{c}$ is also increased from 1.13 MPa (neat PLA) up to $2.93 \mathrm{MPa}$ (PLA+PER). The higher foam stiffness can be explained by differences in the foam morphologies. As revealed by the SEM images in Figure 4 both the cell sizes and homogeneity are different. In the foam of neat PLA very large cells are predominantly visible accompanied by randomly distributed smaller cells. The average cell sizes

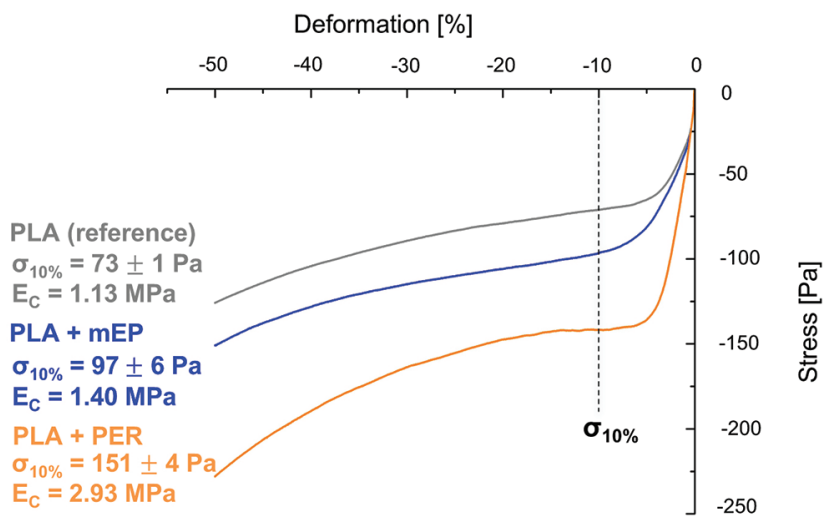

Figure 5: Results of the compression tests of the extrusion foams.

for both modified PLA foams are significant smaller. The improved compression stiffness, is caused by the larger number of smaller and more uniform cells in the modified PLA foams. Most likely the large cells of neat PLA with their thin cell walls are prone to failure under compression, while the denser packed cells of the modified PLA with their increased number of cell walls can withstand a higher compression load.

\section{Conclusions}

In the present study, the melt strength of PLA was increased by a multifunctional epoxide and dicumyl peroxide, respectively. With the two chemical modifiers, it was possible to increase the molecular weight and the 
melt strength. Low density foams were achieved by foam extrusion. Foams from modified PLA revealed a better mechanical performance under compression, which can be related to the morphological features of the foams (i.e., smaller cells and larger number of cell walls).

The cost of the peroxide is approximately just a fifth compared to the commercial chain extender; however, even at a significantly lower concentration of $0.2 \mathrm{wt} \%$, dicumyl peroxide was found to be more efficient than the commercial chain extender Joncryl at $1 \mathrm{wt} \%$ to increase the melt strength. The melt strength was increased from $0.05 \mathrm{~N}$ for unmodified PLA up to $0.19 \mathrm{~N}$ for PLA modified with dicumyl peroxide. Furthermore, structural changes in the chain topology induced by the modifiers lead to more entanglements and thereby to strain hardening at strain rates relevant for foaming. Again, PLA modified with the dicumyl peroxide showed the most pronounced effect. The foamability of PLA was enhanced by the increased melt strength. A further density reduction down to $32 \mathrm{~kg} / \mathrm{m}^{3}$ compared to neat PLA $\left(45 \mathrm{~kg} / \mathrm{m}^{3}\right)$ was possible in foam extrusion. With the chemical modifiers, finer cells in foam extrusion down to $130 \mu \mathrm{m}$ for PLA+PER were obtained due to increased melt strength and strain hardening. The more uniform foam morphology leads to better compressive properties. Thus, the compression modulus of the modified samples was significantly improved compared to neat PLA. The compression strength at $10 \%$ strain was increased more than twice up to $151 \mathrm{~Pa}$ for PLA+PER.

Acknowledgements: The authors kindly like to thank the scientific staff members who contributed with inspiring discussions and all technicians and students for their support during the experiments.

Funding: This study was funded by German Research Foundation DFG (AL 474/33-1 and BO 1600/40-1) and supported by the Bavarian Polymer Institute (BPI).

Conflict of interest: The authors declare that they have no conflict of interest.

\section{References}

1. Aeschelmann F., Carus M., Al E., Bio-Based Building Blocks and Polymers in the World Capacities, Production and Applications: Status Quo and Trends towards 2020. 2015.

2. Dorgan J.R., Lehermeier H., Mang M. Thermal and Rheological Properties of Commercial-Grade Poly (Lactic Acid). S J Polym Environ, 2000, 8(1), 1-9.
3. Carus M., Growth in PLA Bioplastics: A Production Capacity of over 800.000 Tonnes Expected by 2020. nova Institute $\mathrm{GmbH}$, 2012, 02/08/2012.

4. Lim L.-T., Auras R., Rubino M., Processing Technologies for Poly(Lactic Acid). Prog Polym Sci, 2008, 33(8), 820-852.

5. Nofar M., Park C.B., Poly (Lactic Acid) Foaming. Prog Polym Sci, 2014, 39(10), 1-21.

6. Pilla S.; Ki, S.G., Auer G.K., Gong S., Park, C.B., Microcellular Extrusion Foaming of Poly(Lactide)/Poly(Butylene Adipate-CoTerephthalate) Blends. Mater Sci Eng C, 2010, 30(2), 255-262.

7. Mihai M., Huneault M.A., Favis B.D., Rheology and Extrusion Foaming of Chain-Branched Poly(Lactic Acid). Polym Eng Sci, 2010, 50(3), 629-642.

8. Al-Itry R., Lamnawar K., Maazouz A., Reactive Extrusion of PLA, PBAT with a Multi-Functional Epoxide: Physico-Chemical and Rheological Properties. Eur Polym J, 2014, 58, 90-102.

9. Jaszkiewicz A., Bledzki A.K., Van Der Meer R., Franciszczak P., Meljon A., How Does a Chain-Extended Polylactide Behave?: A Comprehensive Analysis of the Material, Structural and Mechanical Properties. Polym Bull, 2014, 71(7), 1675-1690.

10. Di Y., Iannace S., Di Maio E., Nicolais L., Reactively Modified Poly (Lactic Acid): Properties and Foam Processing. Macromol Mater Eng, 2005, 290 (11), 1083-1090.

11. Zhong W., Ge J., Gu Z., Li W., Chen X., Zang Y., et al., Study on Biodegradable Polymer Materials Based on Poly(Lactic Acid). I. Chain Extending of Low Molecular Weight Poly(Lactic Acid) with Methylenediphenyl Diisocyanate. J Appl Polym Sci, 1999, 74(10), 2546-2551.

12. Liu X., Yu L., Dean K., Toikka G., Bateman S., Nguyen T., et al., Improving Melt Strength of Polylactic Acid. Int Polym Process, 2013, 28(1), 64-71.

13. Yu L., Toikka G., Dean K., Bateman S., Yuan Q., Filippou C., et al., Foaming Behaviour and Cell Structure of Poly(Lactic Acid) after Various Modifications. Polym Int, 2013, 62(5), 759-765.

14. Takamura M., Nakamura T., Takahashi T., Koyama K., Effect of Type of Peroxide on Cross-Linking of Poly(l-Lactide). Polym Degrad Stab, 2008, 93(10), 1909-1916.

15. Wei L., McDonald A.G., Peroxide Induced Cross-Linking by Reactive Melt Processing of Two Biopolyesters: Poly(3-Hydroxybutyrate) and Poly(l -Lactic Acid) to Improve Their Melting Processability. J Appl Polym Sci, 2015, 132(13).

16. Corre Y.-M., Maazouz A., Duchet J., Reignier J., Batch Foaming of Chain Extended PLA with Supercritical CO2: Influence of the Rheological Properties and the Process Parameters on the Cellular Structure. J Supercrit Fluids, 2011, 58(1), 177-188.

17. Wang J., Zhu W., Zhang H., Park C.B., Continuous Processing of Low-Density, Microcellular Poly(Lactic Acid) Foams with Controlled Cell Morphology and Crystallinity. Chem Eng Sci, 2012, 75, 390-399.

18. Göttermann S., Weinmann S., Bonten C., Standau T., Altstädt V., Modified Standard Polylactic Acid (PLA) for Extrusion Foaming. In: PPS Europe/Africa Regional Conference 2015, Graz, Austria, 21.-25. September 2015. 2015.

19. Corre Y.-M., Duchet J., Reignier J., Maazouz A., Melt Strengthening of Poly (Lactic Acid) through Reactive Extrusion with EpoxyFunctionalized Chains. Rheol Acta, 2011, 50(7-8), 613-629.

20. Cailloux J., Santana 0.0., Franco-Urquiza E., Bou J.J., Carrasco F., Gámez-Pérez J., et al., Sheets of Branched Poly(Lactic Acid) Obtained by One Step Reactive Extrusion Calendering Process: Melt Rheology Analysis. Express Polym Lett, 2012, 7(3), 304-318. 
21. Meng Q., Heuzey M.-C., Carreau P.J., Control of Thermal Degradation of Polylactide/Clay Nanocomposites during Melt Processing by Chain Extension Reaction. Polym Degrad Stab, 2012, 97(10), 2010-2020.

22. Rytlewski P., Zenkiewicz M., Malinowski R., Influence of Dicumyl Peroxide Content on Thermal and Mechanical Properties of Polylactide. Int Polym Process, 2011, 26(5), 580-586.

23. Liu J., Lou L., Yu W., Liao R., Li R., Zhou C., Long Chain Branching Polylactide: Structures and Properties. Polymer (Guildf), 2010, 51(22), 5186-5197.

24. Södergård A., Stolt M., Properties of Lactic Acid Based Polymers and Their Correlation with Composition. Prog Polym Sci, 2002, 27(6), 1123-1163.

25. Göttermann S., Standau T., Weinmann S., Altstädt V., Bonten C., Effect of Chemical Modification on the Thermal and Rheological Properties of Polylactide. Polym Eng Sci, 2017.

26. Dean K.M., Petinakis E., Meure S., Yu L., Chryss A., Melt Strength and Rheological Properties of Biodegradable Poly(Lactic Aacid) Modified via Alkyl Radical-Based Reactive Extrusion Processes. J Polym Environ, 2012, 20(3), 741-747.

27. Huang Y., Zhang C., Pan Y., Wang W., Jiang L., Dan Y., Study on the Effect of Dicumyl Peroxide on Structure and Properties of Poly(Lactic Acid)/Natural Rubber Blend. J Polym Environ, 2013, 21(2), 375-387.

28. Liu W., Wang X., Li H., Du Z., Zhang C., Study on Rheological and Extrusion Foaming Behaviors of Chain-Extended Poly (Lactic Acid)/Clay Nanocomposites. J Cell Plast, 2013, 49(6), 535-554.
29. Larsen A., Neldin C., Physical Extruder Foaming of Poly (Lactic Acid ) - Processing and Foam Properties. Polym Eng Sci, 2013, 53(5), 941-949.

30. Göttermann S., Weinmann S., Bonten C., Standau T., Altstädt V., Modifiziertes Polylactid Für Die Schaumextrusion. In: 24. Stuttgarter Kunststoffkolloquium, 25.-26. Februar 2015, Stuttgart, 2015.

31. Reignier J., Gendron R., Champagne M.F., Extrusion Foaming of Poly(Lactic Acid) Blown with CO2: Toward 100\% Green Material. Cell Polym, 2007, 26(2), 83-115.

32. Mihai M., Huneault M., Favis B.D., Li H., Extrusion Foaming of Semi-Crystalline PLA and PLA/Thermoplastic Starch Blends. Macromol Biosci, 2007, 7(7), 907-920.

33. Raps D., Köppl T., de Anda A.R., Altstädt V., Rheological and Crystallisation Behaviour of High Melt Strength Polypropylene under Gas-Loading. Polymer (Guildf), 2014, 55(6), 1537-1545.

34. Li X., Ai X., Pan H., Yang J., Gao G., Zhang H., et al., The Morphological, Mechanical, Rheological, and Thermal Properties of PLA/ PBAT Blown Films with Chain Extender. Polym Adv Technol, 2018, 29(6), 1706-1717.

35. Spitael P., Macosko C.W., Strain Hardening in Polypropylenes and Its Role in Extrusion Foaming. Polym Eng Sci, 2004, 44(11), 2090-2100.

36. Mihai M., Huneault M.A., Favis B.D., Crystallinity Development in Cellular Poly (Lactic Acid) in the Presence of Supercritical Carbon Dioxide. J Polym, 2009, 113, 2920-2932.

37. Winterling H., Sonntag N., Polystyrol-Hartschaumstoff. Kunststoffe, 2011. 